\section{A Walk through the Garden: Can a Visit to a Botanic Garden Reduce Stress?}

\author{
Tammy Kohlleppel, ${ }^{1}$ Jennifer Campbell Bradley, ${ }^{2}$ \\ and Steve $\mathrm{Jacob}^{3}$
}

Additional IndeX words. botanic gardens, plant people interactions, stress, leisure.

\begin{abstract}
Summary. Stress has been characterized as an epidemic and has been found to play an important role in causing many diseases. In contrast, people often seek out nature and green spaces to help cope with life stress. Botanic gardens provide opportunities for people to immerse in nature, explore their horticultural interests, and experience recreation and leisure. The literature suggests that all of these activities are effective coping strategies against life stress. This study explored the effectiveness of botanic garden visits as a coping strategy. The findings of this study suggest that botanic gardens could be a place for coping with the effects of stress. Botanic garden visitation, along with gender, stressful life events, perceived health, and selfesteem, was found to be important in explaining reported levels of depression. Data also showed that visitors who received the most benefit of stress reduction were those most needing a coping strategy.
\end{abstract}

$\mathrm{P}$ ublic gardens play an important role in society, whether for leisure, education, conservation, or research (Hubbuch, 1998). Public gardens, including arboreta, botanic gardens, and horticultural gardens are a part of America's museum system and are expanding their societal role by demonstrating that plants are central to human cultural experiences (Solit, 1993). Public gardens offer a unique experience that may impact the individual well being of visitors. However, research documenting the nature and extent of perceived benefit is limited.

Research related to the mental health impacts of botanic gardens is limited. To date, there are only two known studies. However, what little research exists indicates that botanic gardens affect stress. A study by Bennett (1995) found that most visitors to the Brooklyn (New York) Botanic Garden and the New York Botanical Garden (Bronx) perceived decreased stress levels after their visit. Though an innovative study, there are some limitations to this approach. This study only addressed one dimension of a visit to a botanic garden (to escape the urban environment), but a visit to a botanic garden is a multidimensional concept that can be influenced by many components. As stated previ-

\footnotetext{
Florida Agricultural Experiment Station journal series R-07836.

${ }^{1}$ Graduate student, Department of Environmental Horticulture, University of Florida, Gainesville, FL 32611.

${ }^{2}$ Assistant professor, Department of Environmental Horticulture, University of Florida, Gainesville, FL 32611.

${ }^{3}$ Assistant professor, Department of Family, Youth, and Community Sciences, University of Florida, Gainesville, FL 32611.
}

ously, botanic gardens have aspects of nature and leisure. Bennett's research only examined bivariate relationships. This means that only one independent variable was examined at a time. In another study, Owen (1994) measured the blood pressure of visitors to The Wichita (Kansas) Gardens before and after they spent time in the garden. The systolic blood pressure of the visitors decreased significantly after their visit. Though this study clearly shows biophysical stress reduction, we still know very little about the relative importance of the botanic garden visit to other more common coping strategies such as self-esteem and social support and the stress process. The question of how effective a botanic garden visit is in stress reduction has not been established. Both studies cited above, while limited in their methodological framework, do give insight into some of the possible social benefits of botanic gardens. Thus, a goal of this research is to identify the relevance of a visit to a botanic garden in a realistic multivariate model and to provide information to the limited pool of research that currently exists.

Multiple independent variables are examined simultaneously in a multivariate model. These models take into consideration the effect of the other independent variables. This often has the effect of reducing the impact of an independent variable because the model is more realistic in its portrayal of the real world. This research is a correlational design and focuses upon factors that explain variations in behavior for a specific group of subjects. As a correlational research design, control groups are not used. Control groups look at the differences between treatment and nontreatment groups. Here, we are concerned only with those that visit botanical gardens.

Stress is often defined as the emotional and physiological stimulation of an individual that causes adaptive and/or maladaptive responses (Dohrenwend and Dohrenwend, 1970). This is a commonly used definition in the literature and is related to a broad body of research that explores the impact of stress. This body of work is often referred to as stress process research (Pearlin, 1989). The stress process is a model with four main components: individual factors, stressors, mediators (or coping strategies), and outcomes (Aneshensel, 1992; Pearlin, 1989). Individual factors are personal characteristics such as gender, race/ethnicity, age, marital status, education, income and area of residence that influence life choices and exposure to stress (Pearlin, 1989). Stressors are circumstances that cause stress and their associated outcomes. These can include stressful life events, which are circumstances that occur with such magnitude as to significantly alter a person's everyday activities, such as the death of a family member or loss of a job (Aneshensel, 1992). Other important stressors are a person's health and time pressure. Stress mediators are the managers of stress, which are activities or thought processes a person uses to lessen their stress. A visit to a botanic garden would be considered a coping strategy. Stress outcomes, the results of stress (Pearlin, 1989), include substance abuse, mental illness (Lawday, 1991), chronic health problems, and physical illness (Hamberger and Lohr, 1984). The most cited stress outcome and one of the most prevalent mental health problems is depression (Aneshensel, 1992; Devins and Orme, 1985; Pearlin, 1989). Depression is a mood disorder marked by an extreme lack of energy, sense of sadness, helplessness and hopelessness, and negative self-evaluation (American Psychiatric Association, 1994). 
Botanic gardens provide opportunities for recreation and leisure by allowing people to explore their horticultural interests and/or relax in a naturalistic setting. The literature suggests that these activities are effective coping strategies against stress (Caltabiano, 1994; Ulrich et al., 1990; Ulrich and Simons, 1986). The objective of this study was to establish the relative importance of a botanic garden visit as a coping strategy. A theoretical model that places the botanic garden visit in the context of other important coping strategies and stress factors was used, so that the effect of the visit would not be overstated.

\section{Methods}

Three botanic gardens in Florida agreed to participate in this research: Bok Tower Gardens (Lake Wales), Fairchild Tropical Garden (Coral Gables), and Mounts Botanical Garden (West Palm Beach). Participants in the study were visitors to these gardens. Data were collected on one weekday and one weekend day at each garden. Data collection took place between 9 and 18 Apr. 1999. As visitors exited the garden, they were approached and asked to complete a survey, which measured components of the stress process. Visitors were not told the purpose of the survey before completing it. The survey generally took 10 to $15 \mathrm{~min}$ to complete. Three hundred twelve surveys were completed with a $62.3 \%$ response rate. This produces a sample reliability of about $\pm 5 \%$ (Israel, 1992).

A survey instrument was constructed to measure stress levels, individual factors, stressors, stress mediators, and perceived stress. The main factor of interest was perceived stress difference before and after visiting a botanic garden because it reflects the effects of the visit as a coping strategy. Instruments with reliability established by other social scientists were used to operationalize variables where possible. Five Florida botanic garden directors were interviewed in early January 1999 to help define the range and dimensions of survey questions. A panel of experts consisting of University of Florida faculty and botanic garden directors established instrument face validity. A pilot study was conducted 27 to 28 Feb. 1999 at Mounts Botanic Garden to test instrument reliability. To improve reliability of the survey instrument, confusing or redundant questions were eliminated.

The depression indicator was measured using a modified version of the Center for Epidemiological StudiesDepression Scale (CES-D) (Devins and Orme, 1985). The scale consisted of nine statements. Visitors were asked to indicate the extent to which they had felt or experienced any of the items within the past year. Statements included "lack enthusiasm for doing anything", "have poor appetite", and "feel lonely". Responses were on a Likert-type scale, where $1=$ very often, $2=$ somewhat often, and $3=$ not often or never (Likert, 1967). For data analysis, this was reverse coded for ease of interpretation so that a higher score would be associated with higher incidence of depressive symptoms. Depressive symptoms were expected to increase as stress levels increased. The alpha reliability for this index was 0.84 , which represents an adequate degree of reliability. The responses were summed and a mean was taken. The mean for the index was 1.35 .

Three main components of the stress process were used: individual factors, stressors, and stress mediators. These components are part of the stress process (Aneshensel,
1992; Pearlin, 1989). Individual factors consisted of demographic variables such as sex, race/ethnicity, age, marital status, education, income, and area of residence. Visitors were also asked if they were gardeners and/or Florida residents. Stressor variables were measured by stressful life events, perceived health and time pressure. Stress mediators used were social integration, which is interaction with friends and others; self-esteem, which is an assessment of self-satisfaction and confidence (Pearlin, 1989); and perceived stress difference before and after visiting a botanic garden.

Multiple linear regression was used to assess the results of this study. Individual factors, stressors, and stress mediators were each examined separately before being analyzed together. This was done to establish the relative strength of each set of components. Through a series of regression models insignificant variables were removed, significant variables were retained and presented in Table 1.

Significant variables in the final model were coded as follows. Gender was measured as either male or female. A modified version of the Stressful Life Events Inventory was used to assess stressful life events (Cohen and Hoberman, 1983; Dohrenwend and Dohrenwend, 1978; Jacob, 1997; McLeod and Kessler, 1990). Visitors were asked if any of five stressful live events (including birth or adoption of a child; stopped working, lost or quit a job; death) had occurred in their immediate family during the past year. Visitors were then asked to rate their health on a four-point Likert-type scale (Likert, 1967), from $1=$ poor to $4=$ excellent. Selfesteem was measured using a modified format of the Rosenberg Self-Esteem Scale (Rosenberg, 1965). The scale consisted of 10 items answered on a four-point Likert-type scale (Likert, 1967) where $1=$ strongly disagree, $2=$ disagree, $3=$ agree, and $4=$ strongly agree. Items included "I feel that I have a number of good qualities", "I take a positive attitude toward myself", and "On the whole, I am satisfied with myself". The other significant mediation variable in this study was the difference between visitor's perceived stress levels prior to entering the botanic gardens and after their visit. Stress was measured subjectively with two questions: 1) "How stressed are you now?" and 2) "How stressed were you before your visit to the garden?" Participants responded to these questions about their perceived stress level on a 1 to 10 scale (low to high stress).

\section{Results and discussion}

The sample consisted of $34.8 \%$ male and $65.2 \%$ female. Most participants were white $(88.5 \%)$, with a small percentage of Hispanic (6.1\%), black (3.0\%), Asian (1.7\%), American Indian $(0.3 \%)$, and other $(0.4 \%)$. The ages of participants ranged from 19 to 92 years, with a mean age of 51.63 years $(S D=13.74)$. More than half of the participants were married $(65.0 \%)$ followed by those who had never been married (10.9\%), divorced/separated (10.9\%), living with a partner $(6.8 \%)$, and widowed $(6.4 \%)$. The majority of respondents also had a college degree $(55.1 \%)$. Those who had some college or vocational school (28.6\%), completed high school or equivalent (12.2\%), and did not complete high school (4.1\%) followed. Most participants (61.5\%) also had an annual family income of $\$ 50,000$ or more. Only $13 \%$ earned less than $\$ 30,000$ per year. The majority lived in suburban areas $(57.0 \%)$, while only $30.2 \%$ lived in an urban area and $12.7 \%$ lived in a rural area. The majority of visitors 
to the botanic gardens were Florida residents $(74.2 \%)$ and gardeners $(78.8 \%)$.

The regression analysis of the depression index is presented in Table 1 . The regression coefficients $(b)$ are reported along with the standardized regression coefficients (B). The standardized coefficients can be used to compare variables and establishes the strength of each variable in the model (Jacob, 1997).

The model contains the individual factors, stressors, and stress mediators (Table 1$)$. Of the individual factors, only gender $(B=0.137)$ remained statistically significant in the model. The only significant stressor variable in this model was perceived health $(\mathrm{B}=-0.258)$. The two stress mediators, self-esteem $(\mathrm{B}=-0.333)$ and stress difference $(\mathrm{B}$ $=0.172$ ) were also significant. Self-esteem was the strongest predictor in this model with the highest standardized regression coefficient $(B=-0.333)$. Stress difference, which is the measure of the effect of visiting a botanic garden, had the third greatest standardized regression coefficient $(B=0.172)$. Only two predictors were stronger, self-esteem and health, indicating that a visit to a botanic garden was an important coping strategy in this stress model, even when controlling for many other seemingly more important factors. The model had an adjusted $R^{2}$ of 0.295 explaining almost $30 \%$ of the variation in depression. This model had an explained variation that was $33 \%$ or greater than the variation explained in any of the partial models, a significant model improvement (see Kohlleppel, 1999, for earlier analysis).

The delimitations of this study deal with the sample. The study was conducted at three botanic gardens in Florida. Therefore the results of the study can only be safely generalized to these gardens. Since the study was conducted

\begin{tabular}{|c|c|c|}
\hline Variable & $\boldsymbol{b}$ & $\mathbf{B}$ \\
\hline \multicolumn{3}{|l|}{ Individual factors } \\
\hline Female & $0.110^{\mathrm{z}}$ & 0.137 \\
\hline White & 0.095 & 0.076 \\
\hline Age & -0.001 & -0.045 \\
\hline Divorced & 0.092 & 0.075 \\
\hline Education & 0.003 & 0.010 \\
\hline Income & -0.002 & -0.016 \\
\hline Area of residence & 0.041 & 0.068 \\
\hline Florida residents & 0.030 & 0.029 \\
\hline Gardeners & -0.042 & -0.045 \\
\hline \multicolumn{3}{|l|}{ Stressors } \\
\hline Life events & 0.077 & 0.060 \\
\hline Perceived health & $-0.148^{\mathrm{z}}$ & -0.258 \\
\hline Time pressure & -0.025 & -0.040 \\
\hline \multicolumn{3}{|l|}{ Stress mediators } \\
\hline Visit with others & 0.030 & 0.028 \\
\hline Spoke with others & -0.058 & -0.044 \\
\hline Self-esteem & $-0.274^{\mathrm{z}}$ & -0.333 \\
\hline Stress difference & $0.029^{z}$ & 0.172 \\
\hline Constant & $2.533^{z}$ & \\
\hline Adjusted $R^{2 y}$ & 0.295 & \\
\hline
\end{tabular}

${ }^{\mathrm{z}}$ Significant at $P<0.05$.

$\mathrm{y}^{2}=$ coefficient of determination in spring, the results may not hold for other seasons. Regardless of its limitations, this exploratory research is nevertheless important. This study is the only one to date, which examines a visit to a botanic garden as a coping strategy within the multivariate framework of the stress model.

The findings suggest that perceived stress reduction as a result of a visit to a botanic garden (reduced stress difference score) is important in the context of the stress process model as a coping strategy for the study group. It is not as important as self-esteem and perceived health, which are stable characteristics. It would be unrealistic to expect stress difference to have a greater impact on stress than selfesteem and health factors, but, surprisingly, it was more important than any of the individual factors, which have been well established as influential in prior research (Aneshensel, 1992; Pearlin, 1989). The results indicated that visitors who receive the most benefit of stress reduction from a visit to a botanic garden were also those most needing a coping strategy, those persons with higher depression index scores. It is important to note that stress reduction enjoyed by those visiting a botanic garden may only be temporary and likely to change rapidly. Further research is needed to determine how long the stress reduction effects of the visit persist.

\section{Conclusions}

The finding that a visit to a botanic garden can reduce stress levels of study participants is consistent with the research on stress benefits of leisure activities and nature. Many researchers have found that leisure activities decrease stress (Buchanan, 1983; Heywood, 1978; Wankel and Berger, 1991), while others have found that nature can also reduce stress levels (Honeyman, 1987; Ulrich, 1977, 1981). It is also consistent with the research results of Bennett (1995) and Owen (1994) who found a botanic garden visit to reduce visitor stress levels. This research goes beyond these two studies by placing a visit to a botanic garden in context of the stress process model. The findings of this study suggest that botanic gardens could be a place for coping with the effects of stress. Botanic gardens offer a unique experience that impacts the individual well-being of visitors.

\section{Literature cited}

American Psychiatric Association. 1994. Diagnostic and statistical manual of mental disorders. $4^{\text {th }} \mathrm{ed}$. Amer. Psych. Assn., Wash., D.C.

Aneshensel, C.S. 1992. Social stress: Theory and research. Annu. Rev. Sociol. 18:15-38.

Bennett, E. 1995. The psychological benefits of public gardens for urban residents. MS thesis. Univ. Delaware, Newark.

Buchanan, T. 1983. Toward an understanding of variability in satisfactions within activities. J. Leisure Res. 15(1):39-51.

Caltabiano, M.L. 1994. Measuring the similarity among leisure activities based on a perceived stress-reduction benefit. Leisure Studies 13:17-31.

Cohen, S. and H.M. Hoberman. 1983. Positive events and social supports as buffers of life change stress. J. Appl. Social. Psych. $13(2): 99-125$.

Devins, G.M. and C.M. Orme. 1985. Center for epidemiologic 
studies depression scale, p. 144-160. In: D.J. Keyser and R.C. Sweetland (eds.). Test critiques. vol. 2. Westport, Kansas City, Mo.

Dohrenwend, B.S. and B.P. Dohrenwend. 1970. Class and race as status related sources of stress, p. 111-140. In: S. Levine and N.A. Scotch (eds.). Social stress. Aldine, Chicago.

Dohrenwend, B.S. and B.P. Dohrenwend. 1978. Some issues in research on stressful life events. J. Nerv. Mental Dis. 166(1):7-15.

Hamberger, L.K. and J.M. Lohr. 1984. Stress and stress management: Research and applications. Springer, New York.

Heywood, L.A. 1978. Perceived recreation experience and the relief of tension. J. Leisure Res. 10:86-97.

Honeyman, M. 1987. Vegetation and stress: A comparison study of varying amounts of vegetation on countryside and urban scenes. MS thesis. Kan. State Univ., Manhattan.

Hubbuch, C.E. 1998. What is a botanical garden? The Public Garden 13(1):34-35.

Israel, G.D. 1992. Determining sample size. Univ. Fla. Coop. Ext. Serv., Gainesville, Fact Sheet PEOD-6.

Jacob, S. 1997. Pennsylvania rural communities and mental health. PhD diss. Pa. State Univ., University Park.

Kohlleppel, T. 1999. Coping with the effects of stress: Do botanic gardens make a difference? MS thesis. Univ. Fla., Gainesville.

Lawday, D. 1991. Letter from a productive lover of leisure. U.S. News \& World Rpt. 111(6):6-7.

Likert, R. 1967. The method of constructing an attitude scale,p.9095. In: M. Fishbein (ed.). Readings in attitude theory and measurement. Wiley, New York.

McLeod, J.D. and R.C. Kessler. 1990. Socioeconomic status differences invulnerability to undesirable life events. J. Health Soc. Behavior 31(2):162-172.

Owen, P. 1994. The influence of a botanical garden experience on human health. MS thesis. Kan. State Univ., Manhattan.

Pearlin, L.I. 1989. The sociological study of stress. J. Health Soc. Behavior 30:241-256.

Rosenberg, M. 1965. Society and the adolescent self-image. Princeton Univ. Press, Princeton, N.J.

Solit, K.D. 1993. History of the United States botanic garden, 1816-1991. U.S. Congr., Wash., DC.

Ulrich, R.S. 1977. Visual landscape preference: A model and application. Man-Environ. Syst. 7(5):279-293.

Ulrich, R.S. 1981. Natural versus urban scenes: Some psychophysiological effects. Environ. Behavior 13(5):523-556.

Ulrich, R.S., U. Dimberg, and B.L. Driver. 1990. Psychophysiological indicators of leisure consequences. J. Leisure Res. 22(2):154-166.

Ulrich, R.S. and R.F. Simons. 1986. Recovery from stress during exposure to every-day outdoor environments. In: J. Wineman, R. Barnes, and C. Zimring (eds.). The costs of not knowing. Proc. 17th Annu. Conf. Environ. Design Res. Assn. EDRA, Wash., DC.

Wankel, L.M. and B.G. Berger. 1991. The personal and social benefits of sport and physical activity, p. 121-144. In: B.L. Driver, P.J. Brown, and G.L. Peterson (eds.). Benefits of leisure. Venture, State College, Pa.

\section{Restructuring State Major Programs to Address Performance-based Budgeting and Issues Programming}

\author{
Kathryn Gunderson, ${ }^{1}$ Steven A. Sargent, ${ }^{1,4}$ \\ Steven G. Jacob, ${ }^{2}$ George J. Hochmuth, ${ }^{3}$ and \\ Daniel J. Cantliffe ${ }^{1}$
}

Additional index words. cooperative extension service, program planning, program evaluation

Summary. To remain competitive for federal and state funding, state cooperative extension services must proactively incorporate issues programming and performance-based budgeting. State major program (SMP) design teams, which provide linkages between clientele groups and the research base, must conduct needs assessments to adjust to this new atmosphere of accountability. A case study illustrates how one Florida SMP (FL107, vegetable production, harvest, handling and integrated pest management in Florida) restructured its design team to become more flexible and proactive to target a wider range of outcomes. While still in the implementation phase, this model has already resulted in improved communication within the organization, better addressing extension needs at county level while facilitating reporting at the state level.

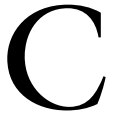

ooperative extension service programs are funded from a variety of sources, primarily from federal, state, and county government. These programs maintain a high level of activity and growth despite the fact that federal spending on agriculture generally has not kept pace with increases in the federal budget (Rogers, 1995). Private organizations and companies also provide significant funding for programming efforts, often in the form of supplies, such as seed for field trials. Cooperative extension services in many states have formed state major programs (SMPs) with the goals of using limited resources more effectively, and to address issues that cross interdisciplinary lines, namely economic, environmental and social. This concept links county extension faculty and statewide extension specialists with similar programming efforts to determine how to best meet the needs of the targeted clientele groups (Taylor and Summerhill, 1993). SMPs are administered at the state level.

Although implementation of SMPs has proven successful in making educational programs more effective, these pro-

This research was supported by the Florida Agricultural Experiment Station, and approved for publication as Journal Series R-08472. The authors are grateful to Howard W. Ladewig, Professor, Agricultural Education and Communication, University of Florida, Institute of Food \& Agricultural Sciences, Gainesville, for useful discussions during the preparation of this paper.

${ }^{1}$ Horticultural Sciences Department, University of Florida, Institute of Food \& Agricultural Sciences, Gainesville, FL 32611.

${ }^{2}$ Family and Youth Sciences Department, University of Florida, Institute of Food \& Agricultural Sciences, Gainesville, FL 32611

${ }^{3}$ North Florida Research \& Education Center, Quincy, FL 32351

${ }^{4}$ Corresponding author; e-mail sasa@mail.ifas.ufl.edu. 